\title{
Incorporating Pre-Service Teachers and Middle School Students in Learning Advanced Integrative STEM Programs
}

\author{
Nayif Awad \\ Sakhnin Academic College, Sakhnin, Israel \\ Email: awad_nayif@sakhnin.ac.il
}

How to cite this paper: Awad, N. (2020). Incorporating Pre-Service Teachers and Middle School Students in Learning Advanced Integrative STEM Programs. Creative Education, 11, 605-615.

https://doi.org/10.4236/ce.2020.114045

Received: March 30, 2020

Accepted: April 25, 2020

Published: April 28, 2020

Copyright (c) 2020 by author(s) and Scientific Research Publishing Inc. This work is licensed under the Creative Commons Attribution International License (CC BY 4.0).

http://creativecommons.org/licenses/by/4.0/

\begin{abstract}
To address the lack of interdisciplinary programs that combine science, technology, engineering and mathematics (STEM), the sound, waves and communication systems (SWCS) program was developed and implemented with different populations: three in-service schoolteachers, 60 pre-service teachers in a college for teacher education, and 120 middle school students. In addition, six pre-service teachers who had learned the swcs course worked in coordination with in-service teachers and taught the course for middle school students. This article presents the program's development and effects, focusing on examining motivational and achievement outcomes. The study aimed at investigating the extent to which participants (both pre-service teachers and school students) could learn/teach an interdisciplinary program, and how the swcs program could affect learners' knowledge and their attitudes towards science class. The study used the mixed method combining both quantitative and qualitative tools. The main results highlight learners' high motivation and knowledge acquisition in learning the program. However, learners still face difficulties, for example, in developing projects and dealing with alternative ideas. Furthermore, the study points to the potential that lies in integrating pre-service teachers in dual learning and teaching experiences.
\end{abstract}

\section{Keywords}

Middle School Students, STEM Education, Sound Waves, Teachers' College

\section{Introduction}

Science education has been criticized for many years because of the separated teaching of STEM concepts (Sanders, 2009), broad use of the traditional teaching method-the passive transfer of knowledge from teachers to students (Barak, 
2014), the striking shortage of qualified teachers, and inadequate preparation of prospective teachers for integrative STEM (Kim et al., 2015).

Although science education research emphasizes a connection between disciplines and offers solutions for integrating various STEM disciplines (Becker \& Park, 2011), only a few programs actually meet this challenge and offer a coherent picture of science (NASEM, 2019). Moreover, the question arises as to how to prepare teachers and provide them with the skills they need to promote STEM integration.

To address the previous issues, the current research included the development, implementation and evaluation of an innovative interdisciplinary course about sound, waves and communication systems (SWCS) in the ICT environment. A five-year study involved teachers, pre-service teachers and middle school students. The research aimed at exploring how the course instruction affected learners' knowledge and motivation, and teachers' development in learning/teaching advanced scientific technological subjects.

\section{Conceptual Framework for the Sound, Waves and Communication Program}

As shown in Figure 1, the major instructional principles or strategies that guided the course development were derived from the educational literature about authentic learning; contextual learning; interdisciplinary learning; simulation-based learning; and project-based learning.

Contextual learning: describes learning that relates to a learner's diverse life contexts-at home, in the workplace, during leisure time, and in social or environmental activities (Greeno, Collims, \& Resnick, 1996).

Interdisciplinary learning: combines the learning of different disciplines (e.g., science, technology, engineering and mathematics) in order to give a clear picture and contribute to the development of students' higher-order thinking skills (Ackerman \& Perkins, 1989).

Simulation-based learning: a software program aimed at demonstrating a scientific concept in an accurate way as it happens in reality. While many researchers (Moreno \& Mayer, 2007; Trundle \& Bell, 2010) reported on its contribution to science learning, others (Rutten et al., 2015) claimed that it might be effective if accompanied by other class activities alongside the teachers' support.

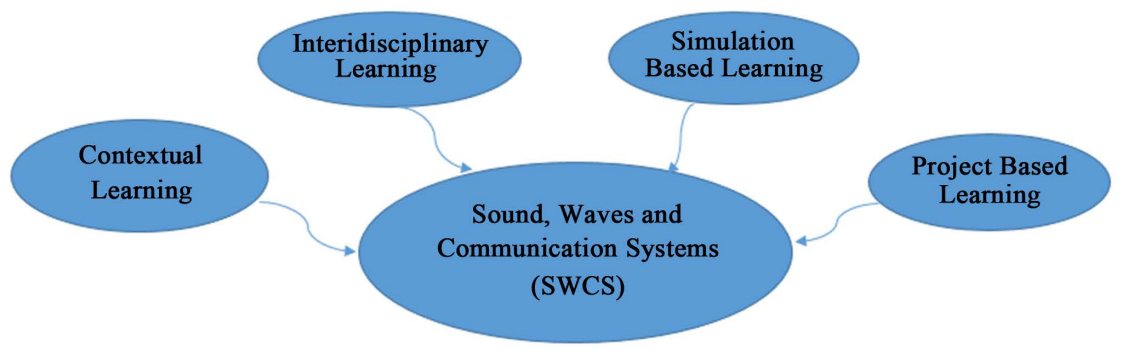

Figure 1. Conceptual framework of the SWCS program. 
Project-based learning: calls to place the learner in an active role where he investigates or solves a major real-life problem that is driven by a research question consisting of a number of tasks and requiring the preparation of a model or product (Barak \& Shachar, 2008).

In addition, two main concepts accompanied the work with students and pre-service teachers, as detailed below:

Active learning: activities associated with learning are inseparable from cognition (Johnson \& Aragon, 2003). Hence, the main idea of active learning is to get students to learn by doing while thinking about the material and about what they are doing (Bonwell, 1996).

Technological pedagogical content knowledge (TPCK): Based on Shulman' work (1987), Mishra and Koehler (2006) added the technological dimension to support intelligent uses of technology in teaching and learning. TPCK develops through an integrative process with classroom practice via planning, preparing and teaching lessons.

\section{The Sound Waves and Communication Systems Course}

Course development: The SWCS course was designed as a 30-hour course for middle school students. Throughout a year, the main researcher (together with his supervisor from Ben-Gurion University of the Negev, Israel) prepared learning/teaching materials for both the students and the teachers: presentations, class activities, lab experiments, technological tools and a user manual. In addition, the research tools were designed. Two cohorts of science teachers who were studying for a second degree in science education at Ben-Gurion University of the Negev experienced the materials and refined them. Later, a pilot study was conducted with 40 middle school students, which helped again to refine the materials and research tools.

Course contents: The current course aimed at providing a deep understanding of SWCS concepts by covering the main subjects: sound as a wave (physics of sound); sound as a system (human ear, audio system - electronic sound systems); and digital sound (sound in computers). Advanced subjects such as noise and electromagnetic waves were discussed as part of the project-based learning phase.

Instructional methods: Most of the class sessions included a 20 - 30-minute theoretical explanation, solving problems, answering questions in which students used the simulations and software programs (audacity), conducting experiments in groups, hands-on work, and building accessible products such as a microphone, speaker and radio kit. The final third part of the course was devoted to students' work on projects about relevant subjects, such as "digital music" and "mobile communications". Most of the students prepared theoretical presentations.

Teachers' mentoring: Three new in-service physics teachers (with $1-3$ years of teaching experience) participated in teaching the course for middle school students. The researcher met independently with the teachers (and the assistant 
teachers) on a weekly basis. These meetings included discussions about SWCS concepts, pedagogical matters, and giving feedback. Two pre-service teachers worked as assistant teachers with each teacher to help him in conducting the lessons.

\section{Methodology}

Three different populations took part in the current study: middle school students, pre-service teachers in college, and teachers who taught the course. To note, teaching the course to middle school students was largely similar to that with pre-service teachers. Ethics and consent information were preserved throughout the research.

Population: The participants comprised six separate groups of 20 students each (7th-graders, age 13 - 14), a total of 120 students. Each group attended two 1.5-hour weekly meetings over 10 weeks. The course was given outside the regular school hours. Three new teachers volunteered to teach the course. All of the teachers had a physics background. Additionally, 60 pre-service teachers in the third year of their bachelor studies in science education took the SWCS course. Among them, six students served as teachers' assistants to teachers in school. About $95 \%$ of the pre-service teachers' population were females aged $19-23$ who had majored in biology and chemistry in high school and had a relatively poor background in learning physics and technology subjects.

Ethics: Although the research was carried out after school hours, it adopted all rules of the Ministry of Education regarding conducting research with students in schools. For example, obtaining the headmaster's and teachers' approval, receiving parental consent, maintaining students' privacy and confidentiality of information, collecting data with students' anonymity, prohibiting taking photographs of the students, and conducting interviews with students in groups. In addition, the pre-service teachers' participation was conducted according to the college's research ethics rules.

Research questions: The questions that guided the current research were:

1) What are the similarities and differences among middle school students and pre-service teachers regarding the learning of advanced scientific-technological subjects such as sound, waves and communication systems? What factors contribute to or hinder their success in learning the subject?

2) What is the impact of studying the subject on students with respect to motivation and interest in learning science and technology, self-efficacy perception of studying scientific-technological subjects, and the desire to learn in an online environment?

3) How does learning SWCS affect teachers professional development and TPCK acquisition?

Research tools: The study adopted a mixed method, combining both quantitative and qualitative tools. More specifically, the data collection included:

- Administering a pre-post semi-structured attitude questionnaire about learners' interest in learning science, the desire to use ICT and self-efficacy to learn science. The questionnaire was based on a study by Fortus and Vedder 
Weiss (2014). An Alpha Cronbach value between 0.6 - 0.75 was received in each of the categories.

- Analyzing the outcomes of a 90-minute exam that participants answered at the end of the course. The exam was composed by the researcher and contained questions about factual, procedural and conceptual knowledge. A panel of experts in science education reviewed it.

- Observing classes and documenting participants' activities in the class.

- Conducting interviews with groups of 2 - 3 participants at the end of the lessons.

- Analyzing class activities and final projects that students submitted in pairs.

\section{Findings}

Participants' achievements in learning scientific-technological subjects: The exam comprised one question about declarative knowledge, two questions about procedural knowledge and two questions about conceptual knowledge. Table 1 presents the participants' outcomes: The participants' achievements were measured on a scale of 0 - 100 (Statistical deviation appears in brackets).

The results show that both the students and the pre-service teachers received relatively high grades in the different types of knowledge, including the conceptual knowledge questions. In addition, the highest grades were achieved in the procedural knowledge question, which reflects the fact that science and technology teachers often emphasize the learning of procedural knowledge.

Participants' attitudes towards learning SWCS: The attitude questionnaire comprised 12 items relating to learners' motivation. The average scores of the participants' answers are presented in Table 2.

The results point to a high level of participants' motivation in pre and post. The t-test results point to significant pre-post differences in middle school students' self-efficacy and pre-service teachers' desire to use ICT resources. In other words, the students showed a significant improvement in their self-efficacy to learn science, while the pre-service teachers presented an increase in their desire to use ICT in learning science.

Findings from participants' work on projects: The participants' projects were checked based on a revised version of Vandervelde's (2006) rubric. To en

Table 1. Participants' outcomes in the final exam.

\begin{tabular}{ccccc}
\hline & \multicolumn{5}{c}{$\mathrm{t}$-test } \\
\cline { 2 - 5 } Type of knowledge & $\begin{array}{c}\text { Middle school students } \\
(\mathrm{n}=120)\end{array}$ & $\begin{array}{c}\text { Pre-service teachers } \\
(\mathrm{n}=60)\end{array}$ & $\mathrm{t}$ & sig \\
\hline Factual Knowledge & $73.05(17.20)$ & $80(22.17)$ & 2.31 & $0.021^{*}$ \\
Procedural Knowledge & $80.00(25.18)$ & $85(36.20)$ & 1.07 & 0.280 \\
Conceptual knowledge & $75.27(20.12)$ & $80(29.18)$ & 1.27 & 0.204 \\
Average & $76.02(13.00)$ & $82(12.70)$ & 2.93 & $0.003^{*}$ \\
\hline
\end{tabular}

${ }^{*} \mathrm{p}<0.05$. 
Table 2. Participants' average scores (statistic deviation) in the attitude questionnaire on a scale of $1-5$

\begin{tabular}{cccccccccc}
\hline & \multicolumn{3}{c}{ Middle school students $(\mathrm{n}=120)$} & \multicolumn{5}{c}{ Pre-service teachers $(\mathrm{n}=60)$} \\
\cline { 2 - 8 } & Pre & Post & $\mathrm{t}$ & $\mathrm{sig}$ & Pre & Post & $\mathrm{t}$ & sig \\
\hline $\begin{array}{c}\text { Interest in } \\
\text { learning science }\end{array}$ & $3.69(0.42)$ & $3.63(0.38)$ & -1.007 & 0.319 & $\begin{array}{c}3.58 \\
(0.29)\end{array}$ & $3.57(0.41)$ & -0.127 & 0.90 \\
$\begin{array}{c}\text { Desire to } \\
\text { use ICT }\end{array}$ & $3.15(0.46)$ & $3.16(0.55)$ & 0.118 & 0.907 & $\begin{array}{c}2.90 \\
(0.51)\end{array}$ & $3.30(0.50)$ & 4.06 & $0.001^{*}$ \\
$\begin{array}{c}\text { Self-efficacy to } \\
\text { learn science }\end{array}$ & $2.62(0.76)$ & $2.92(0.68)$ & 2.889 & $0.006^{*}$ & $\begin{array}{c}2.46 \\
(0.39)\end{array}$ & $2.30(0.41)$ & -1.12 & 0.27 \\
\hline
\end{tabular}

${ }^{*} \mathrm{p}<0.05$.

sure high validity, two veteran science teachers from different schools (having rich experience in science teaching) who were invited to attend the final presentation event were trained to serve as external examiners for the students' projects. Results showed that $55 \%$ of the students and $40 \%$ of the pre-service teachers had difficulties in tackling the task. In the interviews, the participants reported on task complexity and complained that the collaborative work (pair work) was minimal and challenging.

Findings from interviews with the learners: The researcher met with 2 - 3 participants after the lessons and asked questions relating to their motivation and understanding. The interviews lasted 15 - 20 minutes and were recorded. The content analysis method was used to analyze the data. Following this, discourse units (content units) defined as meaningful sentences and statements made by the students were identified, mapped, and categorized to characterize the issues. As part of the verification process, the researcher met with his supervisor to confirm the categorization process and discussed relevance and consistency. The results point to some misconceptions and fragile knowledge that learners still have about sound concepts. Many students provided inaccurate explanations about basic concepts such as sound, analog, sampling and electrical current. In addition, many students had difficulties in answering the research's questions requesting a complete description of natural processes, such as "how sound is produced?" or "how do we hear?" Most of the students' answers were lacking and gaps in their explanations.

Findings from mentoring the schoolteachers: The researcher accompanied three teachers on a weekly basis. He took notes in a diary during the preparation meetings and in the class observations. Additionally, the teachers were interviewed for 45 minutes towards the course end. Findings show that teachers learned new contents, improved their pedagogical knowledge and used the technology better. For example, at the beginning of the course, none of their three teachers had a good understanding of the different subjects such as analog-digital sound conversion and compression of digital sound. However, towards the end of the course, the teachers showed high confidence in teaching these subjects and were able to design different learning activities for their students. In addition, the assistant teachers (six pre-service teachers who worked 
with the schoolteachers) emphasized the importance of having this experience for their career. They started out as assistant teachers, mainly responsible for logistic and administrative issues, and gradually developed until becoming independent teachers with full responsibility about conducting the teaching in the class. The assistant teachers emphasized the different phases they underwent in their professional development, starting from putting focus on understanding new contents, then emphasizing pedagogical aspects and issues related to teaching methods, ending with using educational technologies in class. All the assistant teachers had at least two-three successful experiences in which they were the main teachers, leading the class, and taking full responsibility for teaching the lesson and all other related educational and administrative aspects. Both the schoolteachers and the assistant teachers stated that dealing with new content, having pre-prepared materials, and developmental supervision were very helpful to them.

\section{Discussion}

The current study sheds light on different phases of a five-year project aimed at addressing the lack of integrative STEM programs in middle schools and dealt with issues of preparing prospective teachers and guiding teachers. The research aimed at exploring the participants' motivation and achievements using both quantitative and qualitative tools. The findings showed that the participants (in both populations) managed to learn the SWCS subject, which is considered an advanced technological-scientific subject combining different disciplines such as physics, electronics and computers. Although the pre-service teachers' average scores and declarative scores were significantly higher than the students' scores, it is still interesting to see no significant differences between the students' and pre-service teachers' procedural and conceptual scores. While the achievement differences could be explained rationally by the age gap between the two populations, or because of differences in the instructors who taught the courses, we assume that the course's design (i.e., learning materials and instructional methods) stood behind the similar and close achievements in both procedural and conceptual knowledge.

Moreover, the learners' motivation was high and the participants were interested in learning pre and post the course. As the findings showed, the students significantly improved their self-efficacy and the pre-service teachers' interest in using ICT considerably increased. These results are in line with Kim (2009), showing that integrative STEM education could foster and contribute to students' learning. To the best of our understanding, several factors affected the learning process and contributed to learners' success and interest; these relate to a well-designed learning environment, dealing with authentic contents, and adopting the active learning approach. In addition, the use of diverse instructional methods including theatrical presentations, hands-on work, lab experiments, simulations and projects facilitated the students' learning.

Nevertheless, results from the project work and interviews with the participants pointed out difficulties that some learners had encountered. These diffi- 
culties were about superficial work in several projects, misconceptions and fragile knowledge of scientific concepts. Further, checking back on the students' learning process in class, it became obvious that the students have limited opportunities and serious difficulties in conducting deep discussions and argumentation. The discussions in class sessions (between the learners themselves, the learners and the instructor, or the teachers combined) were notably few, and were even missed. According to Osborne (2010), it is the debate and discussion with others that are most likely to enable new meanings. Hence, learning contents should be tested by rebuttal and counter-arguments. In this context, Chi, Adams, Bogusch et al. (2018) assert in the ICAP theory (Instruction, Constructive, Active, Passive) the teachers' difficulties in implementing instruction for interactive activities. Teachers focus mostly on the condition of collaboration, rather than on the pattern of dialogue. In such a case, the learners' propensity is to focus on the interpretation they found preferable, as opposed to why they found the alternative interpretation less preferable (Henderson, Osborne, Mack Pherson, \& Szu, 2014).

In light of these findings, we formulated a model for the instruction of advanced scientific and technological subjects. The model comprises a combination of Teacher's instruction, Argumentative discussion, Lab work and ICT-aided learning. All these instructional methods are associated with three levels of students' tasks: Practice, Problem solving and Project-based learning, as illustrated in Figure 2. The TALIP ${ }^{3}$ model suggests combining diverse instructional methods within a cyclical process with a gradual increase in the range and complexity of students' tasks.

In Figure 2, the dotted lines towards the center square point to student tasks that should be developed gradually according to the "task taxonomy," a taxonomy created by merging terms from the knowledge taxonomy and the problem-solving taxonomy (Barak, 2013; Kastelan et al., 2014). Based on this, students deal with three levels of tasks:

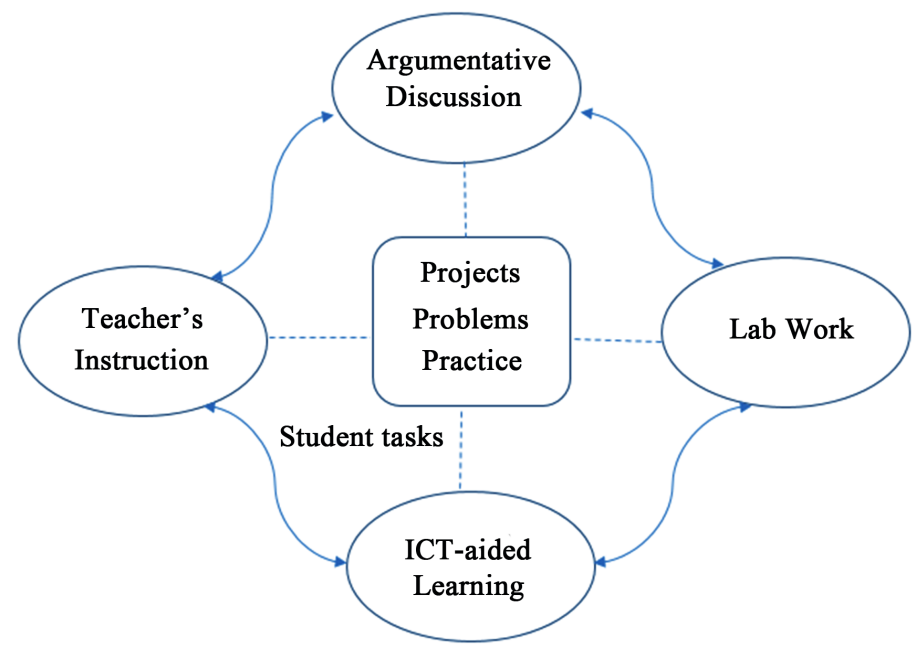

Figure 2. The TALIP ${ }^{3}$ instructional model for teaching advanced science and technology subjects. 
- Practice: Basic exercises, closed-ended tasks in which the solution is known in advance and students can check their answers

- Problem solving: Open-ended small-scale tasks in which students might explore a specific aspect of a wide topic, use different solution methods or arrive at different solutions

- Project-based learning: Broad challenging tasks in which the problem is ill-defined, for example, investigating a complex subject or handling a design task in which the learner should determine the objectives, identify the constraints and choose the solution method

Additionally, the current research highlights the issue of integrating pre-service teachers in both learning and teaching experiences. As mentioned earlier, six pre-service teachers who learned the course in the college taught the course to students in schools. The findings assure the positive impact of such experiences on pre-service teachers' preparation for STEM instruction. According to Adams et al. (2014), teachers feel less knowledgeable about STEM content and less comfortable about teaching STEM than other subjects, since teacher education programs have rarely offered courses to pre-service teachers in which they experience learning that integrates multiple disciplines. Carrier (2009) states that providing pre-service teachers with the opportunity to teach STEM activities could be helpful for their development and self-efficacy. Moreover, Luehmann (2007) emphasized that effective teacher learning occurs when pre-service teachers have multiple opportunities to participate in a carefully scaffolded sequence of reform-based science-learning experiences, both as learners and as teachers. The recent point arises as a main idea in the current study. Actually, based on our observation, we can say that besides learning the course in the college, several factors might help pre-service teachers succeed in teaching the SWCS course. These factors relate to the course characteristics and dealing with innovative contents, pre-preparation of the course materials, and the teachers' guidance and support in the field. Findings showed that teachers' mentoring that was based on customized guidance significantly enhanced teachers' TPCK. These results assert the role that a customized workshop could serve as a professional development framework in bringing curricular innovations into classrooms (Yerushalmi \& Eylon, 2013) and fostering teachers' preparation for applying integrative STEM in schools.

\section{Conclusion}

To address the lack of STEM program, the SWCS was developed and offered both to pre-service teachers and middle school students. Some of pre-service teachers served as learners, and then as teachers in school. The course had a positive impact on learners' achievements and motivation. In addition, the pre-service teaching experience was defined as successful and contributive. The current study suggests that innovative programs, which are derived from the learners' daily life, is a key factor in motivating and attracting learners to learn science and specifically STEM-oriented courses rich in advanced scientif- 
ic-technological subjects.

Moreover, using diverse instructional methods based on the TALIP $^{3}$ model could assist in learning. Special importance should be given to discussions and arguments to overcome misconceptions and alternative ideas. In addition, providing opportunities for pre-service teachers to learn and teach the same contents could be a productive way of reinforcing their knowledge base and improving their teaching skills. Several factors could help in acquiring suitable TPCK that are related to innovative contents, using advanced instructional methods, having pre-prepared materials (in part), and receiving customized guidance.

\section{Conflicts of Interest}

The author declares no conflicts of interest regarding the publication of this paper.

\section{References}

Ackerman, D. B. \& Perkins, D. N. (1989). Integrating Thinking and Learning Skills across the Curriculum. In H. H. Jacobs (Eds.), Interdisciplinary Curriculum: Design and Implementation (pp. 25-38). Alexandria, VA: Association for Supervision and Curriculum Development.

Adams, A. E., Miller, B. G., Saul, M., \& Pegg, J. (2014). Supporting Elementary Pre-Service Teachers to Teach STEM through Place-Based Teaching and Learning Experiences. Electronic Journal of Science Education, 18, No. 5.

Barak, M. (2013). Teaching Engineering and Technology: Cognitive, Knowledge and Problem-Solving Taxonomies. Journal of Engineering, Design and Technology, 11, 316-333. https://doi.org/10.1108/JEDT-04-2012-0020

Barak, M. (2014). Closing the Gap between Attitudes and Perceptions about ICT-Enhanced Learning among Pre-Service STEM Teachers. Journal of Science Education and Technology, 23, 1-14. https://doi.org/10.1007/s10956-013-9446-8

Barak, M., \& Shachar, A. (2008). Project in Technology and Fostering Learning Skills: The Potential and Its Realization. Journal of Science Education and Technology, 17, 285-296. https://doi.org/10.1007/s10956-008-9098-2

Becker, K., \& Park, K. (2011). Effects of Integrative Approaches among Science, Technology, Engineering, and Mathematics (STEM) Subjects on Students' Learning: A Preliminary Meta-Analysis. Journal of STEM Education: Innovations \& Research, 12, 23-37.

Bonwell, C. (1996). Building a Supportive Climate for Active Learning. The National Teaching and Learning Forum, 6, 4-7. https://doi.org/10.1002/tl.37219966704

Carrier, S. J. (2009). The Effects of Outdoor Science Lessons with Elementary School Students on Preservice Teachers' Self-Efficacy. Journal of Elementary Science Education, 21, 35-48. https://doi.org/10.1007/BF03173683

Chi, M. T. H., Adams, J., Bogusch, E. B., Bruchok, C., Kang, S., Lancaster, M., Levy, R., McEldoon, K., Stump, G. S., Wylie, R., Xu, D., \& Yaghmourian, D. L. (2018). Translating the ICAP Theory of Cognitive Engagement into Practice. Cognitive Science, 1-56. https://doi.org/10.1111/cogs.12626

Fortus, D., \& Vedder-Weiss, D. (2014). Measuring Students' Continuing Motivation for 
Science Learning. Journal of Research in Science Teaching, 51, 497-522. https://doi.org/10.1002/tea.21136

Greeno, J. G., Collims A. M., \& Resnick, L. B. (1996). Cognition and Learning. In D. C. Berliner, \& R. C. Calfee (Eds.), Handbook of Educational Psychology (pp. 15-46). New York: MacMillan.

Henderson, J. B., Osborne, J., MacPherson, A., \& Szu, E. (2014). A New Learning Progression for Student Argumentation in Scientific Contexts. In E-Book Proceedings of the ESERA 2013 Conference (Vol. 7, pp. 26-42).

Johnson, S. D., \& Aragon, S. A. (2003). An Instructional Strategy Framework for Online Learning Environments. In S. A. Aragon (Ed.), Facilitating Learning in Online Environments, New Directions for Adult and Continuing Education, (pp. 31-44). Jossey-Bass, San Francisco.

Kastelan, I., Lopez, B. J. R., Artetxe, G. E., Piwinski, J., Barak, M., \& Temerinac, M. (2014). E2LP: A Unified Embedded Engineering Learning Platform. Microprocessors and Microsystems: Part B, 38, 933-946. https://doi.org/10.1016/j.micpro.2014.09.003

Kim, C., Kim, D., Yuan, J., Hill, R. B., Doshi, P., \& Thai, C. N. (2015). Robotics to Promote Elementary Education Pre-Service Teachers' STEM Engagement, Learning, and Teaching. Computers \& Education, 91, 14-31.

https://doi.org/10.1016/j.compedu.2015.08.005

Luehmann, A. L. (2007). Identity Development as a Lens to Science Teacher Preparation. Science Education, 91, 822-839. https://doi.org/10.1002/sce.20209

Mishra, P., \& Koehler, M. J. (2006). Technological Pedagogical Content Knowledge: A New Framework for Teacher Knowledge. Teachers College Record, 108, 1017-1054. https://doi.org/10.1111/j.1467-9620.2006.00684.x

Moreno, R., \& Mayer, R. (2007). Interactive Multimodal Learning Environments. Educational Psychology Review, 19, 309-326. https://doi.org/10.1007/s10648-007-9047-2

National Academies of Sciences, Engineering, and Medicine, NASEM (2019). Science and Engineering for Grades 6-12: Investigation and Design at the Center. Washington DC: The National Academies Press.

Osborne, J. (2010). Arguing to Learn in Science: The Role of collaborative, Critical Discourse. Science, 328, 463-466. https://doi.org/10.1126/science.1183944

Rutten, N., van, V. J. T., \& van, J. W. R. (2015). Inquiry-Based Whole-Class Teaching with Computer Simulations in Physics. International Journal of Science Education, 37, 1225-1245. https://doi.org/10.1080/09500693.2015.1029033

Sanders, M. (2009). STEM, STEM Education, STEM Mania. Technology Teacher, 68, 20-26. https://doi.org/10.17763/haer.57.1.j463w79r56455411

Shulman, L. (1987). Knowledge and Teaching: Foundations of the New Reform. Harvard Educational Review, 57, 1-22.

Trundle, K. C., \& Bell, R. L. (2010). The Use of a Computer Simulation to Promote Conceptual Change: A Quasi-Experimental Study. Computers \& Education, 54, 1078-1088.

Vandervelde, J. (2006). A+ PowerPoint Rubric. http://www.uwstout.edu/soe/profdev/pptrubric.html

Yerushalmi, E., \& Eylon, B. S. (2013). Supporting Teachers Who Introduce Curricular Innovations into Their Classrooms: A Problem-Solving Perspective. Physical Review Special Topics-Physics Education Research, 9, Article ID: 010121. https://doi.org/10.1103/PhysRevSTPER.9.010121 